\section{Gene editing: who should decide?}

Last month's announcement claiming the birth of the world's first genome-edited babies has sparked a furore over how to regulate this cutting-edge technology (see Nature 563, 607-608; 2018, and Nature 564, $5 ; 2018)$. In our view, piling up scientist-led conferences modelled on Asilomar in 1975 (see Nature 526, 293-294; 2015) without any clear consensus is futile.

But lessons can be drawn from another successful case of scientific self-regulation. That is the 1990 Declaration of Inuyama on genetic screening and gene therapy. The Council for International Organizations of Medical Sciences took the lead in calling a conference, made a clear declaration after six days of discussion, and sent it to the World Health Organization, which disseminated it to organizations worldwide. Participants at the conference included biologists, sociologists, psychologists, legal experts, philosophers and religious representatives. Gene therapy could then move from bench to bedside.

International guidelines devised and monitored by scientists could likewise prove useful in regulating genome editing. They should build on previous attempts to do so, for example by the Hinxton Steering Committee in 2015, although the group lacked the necessary diversity (S. Chan et al. Am. J. Bioeth. 15, 42-47; 2015). In return for academic freedom, scientists must regulate themselves - and not just rely on government officials or bioethicists to make such decisions. This regulation would have to involve transparent interaction with citizens.

To restore society's confidence in researchers' professional integrity, rogue germline editing must be stopped by fast and forceful action from genome scientists to lay out transparent rules for gene editing in humans and human embryos. Failure to comply with these rules should incur penalties.

Akira Akabayashi, Eisuke Nakazawa University of Tokyo, Japan.

Arthur L. Caplan New York University School of Medicine, New York, USA.

akirasan-tky@umin.ac.jp

\section{COP24, SDGs: use same stats please}

A draft negotiating text for this year's 24th meeting of the Conference of the Parties (COP24) to the United Nations Framework Convention on Climate Change (UNFCCC) aims to strengthen the reporting of nationally determined contributions (see go.nature.com/2arstr1). It also attempts to regulate national statistical processes - which is the mandate of the UN Statistical Commission and of national statistical offices in member countries. In my view, the UNFCCC should instead track progress towards key climate targets by striving to harmonize the data that it requests with those required by other national and international statistical processes.

Under the UN Sustainable Development Goals (SDGs) agenda (see go.nature. com/2apx8ob), countries must now report on 230 or more indicators and apply a significant subset of statistics covered under the UNFCCC. This means that there is a high risk that public money will be used inefficiently. Different ministries will collect similar information under different definitions and global mechanisms might fund the collection of national statistics in developing countries without sufficient coordination.
UN agencies are investigating how to do this better (see go.nature.com/2ap9fve). New rules for climate reporting should capitalize on, not ignore, individual countries' robust statistical systems and data on socioeconomic drivers, production and consumption patterns, agriculture, forest activities and land degradation.

Francesco N. Tubiello Food and Agriculture Organization of the United Nations, Rome, Italy. francesco.tubiello@fao.org

\section{Funding is not just for the minority}

The US National Institutes of Health $(\mathrm{NIH})$ recognizes the importance of diversity in the country's biomedical research workforce (see, for example, H. A. Valantine and F. S. Collins Proc. Natl Acad. Sci. USA 112 , 12240-12242; 2015), but it still has some way to go to achieve it. In my view, the solution lies in redressing the disparities in NIH funding between institutions.

Success rates for grant applications, as well as award sizes, vary with the race, gender, age and institution of applicants and the state from which they are applying. These differences affect where the grant dollars go (see W. P. Wahls PeerJ 4, e1917; 2016) and lead to funding allocations that are heavily skewed in favour of a minority of geographical regions. The top-funded institution alone gets more dollars than do each of 40 entire states; the top 10 institutions each get more dollars than do each of 35 or more states (based on FY2017 values in NIH RePORTER).

Such concentrations of funding provide diminishing marginal returns, even among 'elite' investigators (M. Peifer Mol. Biol. Cell 28, 2935-2940; 2017). A more egalitarian distribution would support more investigators and increase the diversity of scientific approaches, thereby benefiting biomedical research and the taxpayers who support it. Wayne P. Wahls University of Arkansas for Medical Sciences, Little Rock, Arkansas, USA. wahlswaynep@uams.edu

\section{No trial by media for bullying allegations}

Progressive institutions such as the Wellcome Sanger Institute, where we work, implement antibullying policies that support independent investigations into whistle-blowers' allegations and empower staff to report concerns. However, media coverage of such disputes can be damaging if it is one-sided (Nature 563, 304-305; 2018). It can render the conclusions of the independent investigation irrelevant to public opinion. A potentially constructive process then adversely affects the reputation of the institution, its staff and their research.

Whistle-blowing allegations cannot be fairly scrutinized in public owing to their complexity, and to legalprivacy protections. Narratives that readily garner the media spotlight risk eclipsing grievances that warrant individualized, rigorous and compassionate redress.

To help ensure that new antibullying policies are successful, media coverage needs to be sensitive and balanced, and those who produce it should be aware of its impact.

Grace Collord, Jyoti Nangalia, Luiza Moore Wellcome Sanger Institute, Hinxton, UK. gc8@sanger.ac.uk

CONTRIBUTIONS

Correspondence may be submitted to correspondence@nature. com after consulting the author guidelines and section policies at http://go.nature.com/ cmchno. 